\title{
Hiroshima-Nagasaki, Teherán: la amenaza nuclear
}

\author{
Francisco JaVIER IBISATE \\ Departamento de Economía \\ Universidad Centroamericana (UCA) \\ San Salvador
}

RESUMEN: El quincuagésimo aniversario de la detonación de las bombas atómicas en las ciudades japonesas de Hiroshima y Nagasaki coincide con un momento en el cual la posesión de tecnología nuclear por parte de Irán es vista por los EE.UU. como una amenaza a su poderio. Para el autor, los horrores de Hiroshima y Nagasaki no ban servido para enseñarle a la bumanidad que ninguna guerra es la solución.

ABSTRACT: The fiftieth aniversary of the atomic bombing in the Japanese cities of Hiroshima and Nagasaki is commemorated when the atomic development in Iran is seen as a treat to the U.S. power. According to the author, the horrors of Hiroshima and Nagasaki were not useful to show bumanity that war is not the answer.

\section{El enigma nuclear}

Han coincidido las fechas de dos hechos, a primera vista contradictorios. El pasado seis de agosto se conmemoró en todo Japón el 
sexagésimo aniversario de las bombas atómicas (Little Boy y Fat Man) que el Gobierno de Estados Unidos lanzó sobre las ciudades de Hiroshima y Nagasaki, segando las vidas de más de 350.000 civiles indefensos. Theodore Van Kirk, que piloteó la superfortaleza Enola Gay, seis décadas más tarde afirma que "las guerras no solucionan nada y que no deberían haber bombas atómicas”. El mismo 6 de agosto de 2005, se publicaron los siguientes titulares: "Irán califica de inaceptable la propuesta europea para resolver la crisis nuclear" (Le Monde) e "Irán rechaza el plan de cooperación de la UE para frenar sus aspiraciones nucleares" (El País)

Sesenta años separan ambos hechos, que pueden calificarse de históricos porque plantean un enigma nuclear. "Japón pide a la ONU que garantice un mundo libre de armas nucleares" (El Mundo, Madrid, 6 de agosto de 2005) "Sesenta años, después sigue abierta la llaga de Hiroshima" (Le Figaro, 7 de agosto de 2005) Por su parte, "Kofi Annan se opone a la proliferación atómica, en su mensaje leído en Hiroshima" (Le Monde, 7 agosto 2005) Durante sesenta años el poder de veto en el Consejo de Seguridad de Naciones Unidas ha sido privilegio de las cinco primeras potencias que desarrollaron la energía nuclear hasta el nivel de bomba atómica. Son los tiempos de la guerra fría; Estados Unidos, Francia e Inglaterra versus la URSS y China, cuando las ojivas nucleares eran armas disuasivas, de manera que ninguno de ambos bloques —ideológicamente irreconciliables - se extralimitara en sus prácticas militares. Las políticas gubernamentales se asentaban en la 'atrición', el miedo a las consecuencias de un conflicto nuclear, pero nunca en una contrición, es decir, en la persuasión de que la guerra no es la solución. Históricamente, los cinco miembros permanentes del Consejo de Seguridad de la ONU han sido los cinco mayores exportadores de todo tipo de armas de destrucción masiva, al mismo tiempo que - unos y otros - atizaban y subvencionaban guerras civiles en todos los rincones del mundo.

Esto ha generado que, al finalizar el siglo $\mathrm{XX}$, se vuelvan a repetir los mismos tipos de delitos cometidos por la locura nazi y que se definen en el artículo 6 del tribunal de Nüremberg: 6a) Crímenes contra la paz; 6b) Crímenes de guerra; 6c) Crímenes contra la humanidad, a partir de los cuales Naciones Unidas definió el delito de genocidio. (Entorno económico mundial. UCA Editores; pp. 63-65) A solicitud del Secretario General de Naciones Unidas, Kofi Annan, 94 países de los 191 miembros de la ONU han ratificado los estatutos de la Corte Penal Internacional (CPI), que juzgará crímenes de guerra, crímenes de lesa humanidad y genocidios 
cometidos luego del $1^{\circ}$ de julio de 2002. Sólo cinco de los quince países miembros del Consejo de Seguridad de Naciones Unidas han ratificado los estatutos de la CPI y tres de los cinco miembros permanentes tampoco los han ratificado: Estados Unidos, Rusia y China. El enigma nuclear significa que - como norma general - la mayoría de países poseedores de la bomba atómica se niegan a ratificar los estatutos de la Corte Penal y presionan a otros gobiernos dependientes para que tampoco los ratifiquen (caso Estados Unidos y El Salvador). También significa que el grupo de países que más presionan a Irán para que no desarrolle la energía nuclear más allá del uso civil (generación de electricidad), todos ellos disponen de la bomba atómica y algunos de ellos han desarrollado modernas armas nucleares más sofisticadas y tanto o más mortíferas. El enigma nuclear significa que - seguramente- Estados Unidos no hubiera invadido a Irak si Saddam Hussein hubiera tenido la bomba atómica. ¿Dónde está ahora la seguridad: en la fuerza del derecho o en el derecho de la fuerza?

\section{Un legado para la humanidad}

Tana Oshima, redactora del citado artículo en el diario El País, dice que "los supervivientes temen que aquella tragedia caiga en el olvido y se vuelva a repetir". "Pocos minutos antes, en un oscuro presagio, los B-29 habían aparecido en el cielo sobrevolando la ciudad (Hiroshima) en su hora punta de actividad. Una de las superfortalezas, llamada Enola Gay, transportaba la bomba de uranio que EE.UU bautizó con el nombre de Little Boy. No hubo tiempo para huir; un fulminante resplandor desgarró el cielo y, al instante, se hizo la oscuridad. 120.000 personas murieron en el acto y otras decenas de miles perecieron al finalizar el año. Gran parte de Hiroshima quedó aniquilada, borrada del mapa. Tres días después la misma pesadilla se repetía en Nagasaki... 73.884 personas murieron al instante en Nagasaki y otras 75.000 perecieron en los meses siguientes. Era difícil imaginar que aquella desgracia pudiera proceder de la mano del hombre; incluso algunos creyeron que aquel era un fenómeno de la galaxia".

¿Por qué recordar este genocidio sesenta años más tarde? Los supervivientes de Hiroshima-Nagasaki ("bibakusha") se afanan porque los jóvenes japoneses no pierdan la memoria del pasado. Desde los años de la primera guerra mundial Japón "había practicado una política brutal de expansión imperialista y colonización que quitó la vida a millones de asiáticos (chinos, coreanos, rusos). La locura suicida del primer ministro 
Hedeki Tojo, patético admirador de Hitler y alentador de los kamikazes, parecía capaz de llevar al límite su lema propagandístico de "cien mil corazones de Japón laten como una única familia en esta guerra emprendida para la supervivencia del Imperio". Tana Oshima recuerda que "la saturación de la propaganda nacionalista impedía a la mayoría del pueblo saber que el país estaba perdiendo la guerra. Las bombas y el holocausto vinieron brutalmente a poner fin a una contienda fanática, larga y penosa que el pueblo estaba deseando terminar. El país quedó traumatizado y con sus recursos agotados. Sesenta años después, las bombas atómicas continúan matando en silencio. Las huellas de las radiaciones perduran en la llamada "enfermedad atómica" como para que el hombre nunca olvide lo que fue capaz de hacer. Ese es el mensaje que lanzan incansablemente Hiroshima y Nagasaki cada año por estas fechas, cuando el mundo parece dispuesto a recordar".

Tana Oshima plantea el problema con un sugerente subtítulo: "Una paz amenazada por el olvido". "Actualmente, los propios japoneses empiezan a enterrar su pasado en la ignorancia de las nuevas generaciones. Los supervivientes protestan, unos con resignación y otros con ímpetu, que el Japón de hoy ha olvidado el precio que se pagó por conseguir la paz. Uno de los debates que más atemoriza a los hibakusha es la posible reforma del principio pacifista de la Constitución japonesa, vigente desde la ocupación estadounidense del general McArthur, que impide al país participar en cualquier conflicto armado que no sea en defensa propia". Ahora es la Administración Bush, que mantiene 40.000 marines en el archipiélago, la que "presiona a Japón para que sus tropas puedan participar activamente en los conflictos internacionales. La idea beneficia a la conservadora clase política nipona, que ve en el 'rearme' (Japón cuenta ya con uno de los ejércitos mejor dotados del mundo, pero limitado a la autodefensa) una forma de impulsar el nacionalismo. Sin embargo, la sola posibilidad levanta la ira tanto de los supervivientes de las bombas como de los vecinos asiáticos que sufrieron las agresiones del militarismo nipón. Para los bibakusha, la única esperanza de preservar la paz es mantener viva la memoria de lo que ocurrió, y esa esperanza se desvanece. Dentro de un tiempo ya no estarán aquí para enseñar al hombre sus errores, advierten los supervivientes ante la mirada dormida de los jóvenes.... Y son pocos los que conocen las atrocidades que el ejército del Sol Naciente cometió en Asia". (Tana Oshima: "Un legado para la humanidad". El País, 6 de agosto de 2005) 
El Secretario General de Naciones Unidas, Kofi Annan en su discurso dirigido al alcalde de Hiroshima, ha aprovechado la oportunidad para advertir sobre el peligro de la proliferación atómica mundial: "Sin una acción concertada, la comunidad internacional corre el riesgo de verse confrontada a una cascada de proliferación nuclear", incluso sin contar las ambiciones atómicas de Corea del Norte e Irán. "El mundo ha hecho pocos esfuerzos por responder a este nuevo desafío", lamenta el Secretario General. Por su parte el alcalde de Hiroshima pide a la ONU encargar a un comité especial estudiar las medidas oportunas para desterrar las armas nucleares, a fin de despejar el impasse a que ha conducido a la conferencia sobre la revisión del Tratado de No Proliferación (TNP), en razón de la "regla del consenso" que allí prevalece. A partir de las recomendaciones de este Comité, "la Asamblea General debe adoptar antes del año 2010 medidas específicas para la eliminación de armas nucleares de aquí al 2020. Las potencias nucleares son una amenaza para la supervivencia de la humanidad", dijo el alcalde.

Al interior de las instituciones gubernamentales japonesas hay posiciones encontradas en torno a la revisión de la Constitución. El primer ministro Junichiro Koizumi asegura que Japón quiere seguir siendo "país pacífico, no nuclear" y "continuará respetando la Constitución pacífica, adhiriéndose a los tres principios no nucleares - no fabricar, no poseer $y$ no mantener armamento atómico dentro del país". Sin embargo, este primer Ministro ha hecho campaña para que se revise la Ley fundamental, a fin de que la fuerza militar pueda intervenir en el extranjero, de acuerdo a la presión de G. W. Bush. El presidente de la Cámara Baja, Yohei Kono, invita a los japoneses a reflexionar su responsabilidad: "Hemos cometido un error al seguir la 'ruta de la guerra'... Hemos privado de su independencia a Corea y hemos intervenido en China. Uno de los resultados de esta política fue el lanzamiento de la bomba atómica”. Esto es una velada crítica a Junichiro Koizumi. (Kofi Annan se opone a la proliferación atómica en su mensaje a Hiroshima". Le Monde, 7 de agosto de 2005)

Ha sido una crítica casualidad que en la fecha del 6 de agosto de este año se haga memoria de ambos hechos históricos relacionados con la amenaza nuclear. Sesenta años después de Hiroshima-Nagasaki la amenaza nuclear no ha desaparecido. "El mundo de hoy es incluso más peligroso que el de antes. Las armas nucleares, que proliferan, siguen amenazando la seguridad internacional como lo prueban las crisis norcoreana e iraní.

Hiroshima-Nagasaki, Teherán: la amenaza nuclear 
Más preocupante todavía para la comunidad internacional es el riesgo de un 11 de septiembre nuclear, recientemente evocado por la Agencia Internacional de la Energía Atómica (AIEA), en la hipótesis de que al arma atómica cayera en manos de terroristas. "La naturaleza de la amenaza nuclear ha cambiado y no se ha adaptado el sistema del cual dispone la comunidad internacional para dar una buena respuesta", dice la antigua embajadora Kuniko Inoguchi". ("Sesenta años después, permanece abierta la llaga de Hiroshima”. Le Figaro, 7 de agosto de 2005)

\section{El peligro de la proliferación atómica}

La proliferación atómica crece cuantitativa y cualitativamente luego de Hiroshima-Nagasaki, porque en la conferencia de Yalta, 1945, ambos bloques reinician la teoría de la coexistencia pacífica: "si vis pacem para bellum" (si quieres la paz, prepara la guerra), dando curso a la carrera armamentística. En 1970 se estaba gastando, a escala mundial, un millón de dólares por minuto en generar poder destructivo, cantidad que se duplica al iniciarse la era de la Perestroika. Era de esperar que la proliferación atómica descendiera luego de la firma del decreto de Minsk, 1991, que ponía fin a la URSS, al pacto de Varsovia y al mismo CAEM.

Luego de los atentados del 11 de septiembre no vamos a tener realmente un descenso en la proliferación atómica, sino un cambio de uniforme. En el viaje que George W. Bush realizara en mayo de 2002 por cuatro países de Europa (Berlín, Moscú, París y Roma) para convencer a sus Gobiernos de que el peligro número uno del mundo era el 'terrorismo', Bush y su homólogo ruso Vladimir Putin firman un acuerdo para la reducción de los arsenales nucleares de ambas potencias a un nivel máximo de 2.200 ojivas de aquí a 2012. Un descenso significativo de las 6.000 ojivas entonces existentes. Norteamérica anuncia que almacenará sin desmantelar las ojivas retiradas, mientras que Rusia guarda la posibilidad de instalar múltiples cabezas en los misiles conservados. Para Rusia este pacto es ventajoso porque no cuenta con recursos financieros para mantener su actual arsenal y porque espera nuevas ayudas económicas luego de este acuerdo que "pone fin a la guerra fría". Putin dijo que "Rusia y los Estados Unidos han logrado desde hace un año crear un clima de mutua confianza y comprensión, demostrando que nuestros países no son adversarios".

La Declaración de Roma, de mayo de 2002, se abre frente a un escenario no muy halagador: "Vivimos un mundo nuevo... donde nuevas amenazas 
y desafíos exigen respuestas cada vez más unidas. Por esta razón los Estados miembros de la OTAN y la Federación de Rusia abrimos un nuevo capítulo en nuestras relaciones..." A la hora de los brindis los jefes de Estado levantaron su copa y echaron su estribillo: "El terrorismo tiene unos medios excepcionales que requieren una respuesta excepcional", dijo J. Chirac. "El pueblo británico ya no teme al ruso, pero los dos temen al terrorismo", señaló Blair. No podeis vencernos, no teneis ninguna oportunidad" espetó Berlusconi a los terroristas. "Los valores no se defienden solos. No debemos esperar sentados a ser agredidos", añadió J. M. Aznar. La mayoría de líderes destacaron el protagonismo de Rusia, de Putin en particular, que, aparte de comprometerse a la defensa de la democracia y la libertad, tendrá que enfrentar algunos recelos internos de la clase militar. Puesto que Rusia se une a este esfuerzo europeo, Putin exigió un 'respeto recíproco'. 'No podemos pensar Rusia fuera de Europa". (Realidad 2002; pp. 436 y 440)

Luego del ataque terrorista a la escuela de Beslan, Rusia, septiembre 2004, V. Putin se decide a poner en obra el fortalecimiento del poder central de los ministerios de Seguridad, Defensa e Interior. Más de cuarenta proyectos de ley se presentan al parlamento para luchar contra el terrorismo internacional. Con fecha 17 de noviembre, Putin anuncia que Rusia iba a contar pronto con nuevos sistemas de armas nucleares, que "no existen y no existirán en los próximos años en otras potencias nucleares. Seguimos con las investigaciones y ensayos de sistemas nucleares más modernos. Estoy seguro de que en los próximos años serán parte de nuestro equipo nuclear". De acuerdo a los expertos parece que se trata de misiles de $10.000 \mathrm{kms}$. de alcance. "Bastaría con que descuidáramos nuestra atención a estos componentes de nuestra defensa, que forman parte de nuestro escudo de misiles nucleares, para que nos encontráramos enfrentados a otras amenazas". Putin no especifica cuáles son esas otras amenazas, porque misiles de $10.000 \mathrm{kms}$ de alcance no es el arma más apropiada para vencer al terrorismo; el terrorismo no se rige por los manuales convencionales de guerra. ("Nostalgia a la rusa". Le Monde, 18 de noviembre de 2004)

El título de Le Monde hace referencia a la nostalgia de la Gran Madre Rusia, que no permite nuevos desprendimientos republicanos de los ya firmados en el acuerdo de Minsk, diciembre 1991. Las amenazas vienen por otro lado. La Duma había aprobado una serie de medidas que organizan un mayor control de extranjeros, limitan la circulación de

Hiroshima-Nagasaki, Teherán: la amenaza nuclear 
personas y prevén una censura de los medios de comunicación en caso de crisis. A la explicación solicitada por C. Powell y G. W. Bush, S. Laurov respondió: "Estas medidas se basarán en la Constitución de nuestro país y continuarámos con la defensa de nuestros intereses legítimos a través de un diálogo amigable, la cooperación y la ayuda, más que por la confrontación. Se trata de reforzar la unidad del país y de su pueblo para luchar contra el terrorismo y garantizar una existencia segura a nuestros ciudadanos en libertad y democracia". Por su parte, Putin acusó a Occidente por el doble rasero en cuestiones de terrorismo, persiguiendo por un lado a los fundamentalistas islámicos en Afganistán e Irak, mientras "dan refugio a los terroristas chechenos", que piden la independencia de Rusia. "Dar cobijo y apoyo a terroristas, a sus cómplices y promotores les sirve de justificación y les anima a cometer crímenes". (El País, 4 de diciembre de 2004) Hay tensiones entre los signatarios del Tratado de Roma.

El 6 de diciembre de 2004, La Prensa Gráfica nos da una impresionante noticia: " 25 mil árabes listos para ataques suicidas. Miles se reclutan como kamikazes en Teherán para Irak". Irán es considerado el "gigante musulmán” y cuenta con el ejército islámico más poderoso de la región. El presidente pakistaní Pervez Musharraf estimó ayer que el mundo es "menos seguro" desde la invasión de Irak por las tropas estadounidenses y británicas. Él se opuso a la invasión de Irak, pero agregó que "los soldados estadounidenses no deberían retirarse de Irak porque se crearían aún mayores problemas" (p. 42). Esto explica que Estados Unidos y otros países europeos se opongan a que Irán avance hasta el estadio final del enriquecimiento del uranio.

\section{Las nuevas armas nucleares y el futuro de la humanidad}

Eduardo Subirats plantea en este artículo los problemas que pueden derivarse de la cumbre tenida en Nueva York, en mayo de 2005, donde el Tratado de No Proliferación Nuclear no acaba de dar respuesta a los objetivos deseados. "Los medios globales de comunicación han guardado, por lo demás, un cauteloso silencio sobre los significados de la muerte de este tratado que debía regular el desmantelamiento de las cabezas atómicas activas existentes, la prohibición global de investigaciones y experimentos conducentes a incrementar el potencial destructivo nuclear no de una $\mathrm{u}$ otra, sino de todas las naciones, y la interrupción de los tráficos estatales o paraestatales de los componentes materiales y técnicos de la guerra nuclear avanzada". 
"Durante las negociaciones de "no proliferación", los grandes titulares de la prensa y la televisión globales los han monopolizado como era de esperar, las agresivas consignas de la Administración norteamericana contra las tentativas de soberanía nuclear de Corea del Norte e Irán (que la invasión de Afganistán y las dos sucesivas guerras contra Irak han justificado con contundentes argumentos) $\mathrm{Y}$ bajo los fuegos cruzados de halcones americanos, comunistas coreanos y chiíes iraníes se ha enmudecido confortablemente el conflicto fundamental que genera la escalada nuclear: el conflicto político y económico entre las cinco superpotencias nucleares y la gran mayoría de Estados no nucleares. Allí donde estos últimos exigen un desarme total, los superpoderes atómicos responden con nuevas tecnologías, estrategias y tests de efectos contaminantes globales".

Si por una parte se habla de reducir el número de cabezas nucleares, una herencia obsoleta de la guerra fría, "lo que se pretende desarticular no es la amenaza del holocausto nuclear, sino sus superadas tecnologías. Las metáforas que la jerga tecno-industrial-militar del Pentágono utiliza para documentar este proyecto modernizador son elocuentes por sí mismas: "entirely new types of nuclear warheads" (tipos enteramente nuevos de ojivas nucleares); "bunker-buster warbeads" (ojivas revientabunkers); "low-yield, precision-guided nuclear weapons" (armas nucleares de precisión y baja potencia); "usable nuclear weapons" (armas nucleares utilizables); "earth penetrating weapons" (armas que penetran bajo tierra). La visión histórica que subyace a estas definiciones es brutalmente elemental. Ya no existe una lógica binaria que legitime el principio de destrucción mutua total entre superpotencias contrincantes. Las nuevas soberanías nucleares se extienden a lo ancho de territorios aleatorios de fronteras indefinidas, sus sujetos son política e ideológicamente móviles, sus tácticas se han vuelto aleatorias. Las nuevas armas tienen que ser, por este mismo motivo, a la vez flexibles y específicas. Sus efectos letales deben minimizar su visibilidad mediática".

"Los nuevos objetivos nucleares no son ciudades, sino búnkers e instalaciones industriales. Por todo lo demás, estas nuevas tecnologías nucleares están clasificadas estratégica y jurídicamente como convencionales, porque sus objetivos son dispositivos militares y se han legitimado en el Senado de los Estados Unidos como armas de efectos radiactivos controlados. Seguirán siendo armas de destrucción masiva que dejarán por todo legado una contaminación indefinida. Pero no será posible 
contabilizar sus víctimas, Sus consecuencias materiales tampoco son espectaculares. Y la ya fragmentada resistencia intelectual y civil a la guerra nuclear quedará aún más debilitada con ello"

De esta forma se ha definido un nuevo tipo de guerra nuclear. "Los cientos de toneladas de misiles de alta precisión con uranio empobrecido que se han lanzado en Irak, los Balcanes y Afganistán son solamente un anticipo de los futuros campos de batalla. El uranio empobrecido es un residuo tóxico de la industria nuclear utilizado como metal denso de alta capacidad de penetración en búnkeres, instalaciones industriales y vehículos acorazados. Pero su vida radioactiva es indefinida y su oxidación genera un polvo microscópico que se disemina en la atmósfera y cuya inhalación provoca el cáncer pulmonar y la leucemia. Cientos de miles, principalmente niños, han muerto en aquellas regiones como consecuencia de estas bombas nucleares sucias, de acuerdo con informes forenses de las Naciones Unidas. Bombas nucleares sucias, armas nucleares híbridas, estrategias nucleares mixtas, y el silencio civil e intelectual: éste es el balance de la última conferencia de Naciones Unidas que exhibe las palabras "No proliferación" en su bandera. Su esperado fracaso ha significado una victoria para las posiciones globales más beligerantes: las de Corea del Norte y Washington. También ha puesto de manifiesto la ausencia de una voluntad civil e intelectualmente articulada para poder hacer frente a la carrera científica, técnica, industrial y militar hacia la extinción de la humanidad". (Subirats E.: "Las nuevas armas nucleares y el futuro de la humanidad". El País, 22 de julio de 2005)

\section{De Irak a Irán "y tiro porque me toca"}

En su discurso sobre el estado de la nación, del 3 de febrero 2005, Bush habló de la nueva situación política de Irak que abre una nueva fase de nuestra misión en ese país. El presidente norteamericano aprovechó la ocasión para lanzar una advertencia a Irán porque sigue siendo "el principal Estado en el mundo que sostiene el terrorismo y porque quiere dotarse con armas nucleares, al mismo tiempo que priva a su pueblo de la libertad que busca y que merece". Dos días más tarde Condoleeza Rice, de visita en Berlín, expresó su preocupación por las intenciones del gobierno de Irán. "Los iraníes no han demostrado hasta el momento estar dispuestos a observar sus obligaciones internacionales. Esto es preocupante, no sólo para Estados Unidos, porque esta inquietud la ha planteado la Agencia Internacional de la Energía Atómica (AIEA) y en otros coloquios mundiales". Sin embargo, la Secretaria de Estado añadió que "no era parte de la agenda del día un ataque a Irán". 
Aunque un ataque a Irán no sea parte de la agenda de febrero, esta simple afirmación nos recuerda la resolución 1441, del 8 de noviembre de 2002, que conmina al gobierno de Irak por no cumplir con las condiciones de desarme". El 29 de enero 2005 Mahomed el Baradei, director general de la AIEA, dijo que "Irán está cooperando positivamente en las inspecciones nucleares. Hay negociaciones en curso entre la Unión Europea e Irán y se advierte un progreso importante. Tenemos que garantizar a aquellos países que lo necesitan el acceso al uranio enriquecido con fines pacíficos. Y al mismo tiempo debe aprobarse una moratoria general de cinco años para que nadie trate de enriquecer uranio". Mahomed el Baradei advirtió a Estados Unidos que "un ataque militar en territorio iraní sólo empeorará las cosas".

Esta afirmación tiene su razón de ser. El senador republicano Saxby Chamblix explicó que "el gobierno de Bush contempla que Estados Unidos va a ser el objetivo de un próximo ataque terrorista y que probablemente se usará algún arma de destrucción masiva. La capacidad nuclear de algunos estados podría pasar a manos de terroristas, como el grupo Al Qaeda, y esto nos parece relevante porque esos grupos intentarían usarla". Esta es la lógica simplista de un senador republicano para acusar a un país. Por ello, el ministro de Asuntos exteriores iraní, Kamal Jarrazi, explicó cuáles con las diferencias entre Irán y Corea del Norte. "Es una manipulación afirmar que ambos países tienen la misma conducta. Irán es parte del Tratado de No Proliferación Nuclear. Corea del Norte se ha salido de él; Irán ha firmado el protocolo adicional que refuerza las inspecciones. Corea del Norte no lo ha rubricado; la AIEA envía sus inspectores; los inspectores no pueden entrar en Corea del Norte. Pero es que Corea del Norte reconoce su deseo de fabricar armas nucleares, e Irán afirma que no es su objetivo. Discrepo de lo que dice el senador. Si Irán tuviera energía nuclear, eso no supondría que ésta caería en manos de los terroristas. Usted está haciendo acusaciones sin prueba. Es necesario recordar que Al Qaeda fue creado para hacer daño a Irán". A mediados del mes de enero, el vicepresidente Dick Cheney afirmó con claridad que Irán figura a la cabeza de-las preocupaciones de Estados Unidos, y agregó que Washington temía que los israelitas tomaran la iniciativa para destruir las instalaciones nucleares iraníes. El portavoz del ministerio de Asuntos Exteriores iraní dijo que las amenazas de Cheney muestran que "el cabildeo sionista es poderoso en Estados Unidos" y que esta política "va a aislar más a Estados Unidos". (ECA 2005; 229230) 


\section{Irán, el chivo expiatorio nuclear}

De acuerdo a la nota editorial de Realidad, dedicada al tema de "la crisis energética", el inmenso tonelaje de residuos nucleares ha contaminado, de forma indefinida, nuestro medio ambiente y "no existe aún una solución acerca de qué hacer con esta basura nuclear" (Realidad, 2005; p. 203) Incluso desde el punto de vista medioambiental, los países no nucleares tienen sobrada razón para oponerse a esta carrera atómica, en cualquiera de sus fases, por ser gestora de lentas y masivas muertes de millones de civiles indefensos. Tienen más razón para oponerse a aquellos técnicos-investigadores militares que, sin reducir sus arsenales de ojivas 'Hiroshima-Nagasaki', han inventado y aplicado nuevas 'armas de bolsillo' revientabunkers que, de forma convencional y controlada, siegan miles y miles de vidas ocultas a las estadísticas. $\mathrm{El}$ actual dilema atómico parece ser determinar qué gobiernos son dignos de utilizar la energía nuclear sólo con fines civiles (electricidad) y cuáles no son 'confiables' y no ofrecen tal garantía. El tribunal evaluador no quiere competencia.

Irán, nación catalogada como miembro del 'eje del mal' de acuerdo al 'imperio del bien', anuncia públicamente en plena sesión de la ONU "su determinación de proseguir sus actividades en todo el ámbito legal de la energía nuclear, incluido el enriquecimiento de uranio, exclusivamente con fines pacíficos". (Le Monde, 3 de mayo de 2005) Naciones Unidas ha tenido a bien esperar el resultado de las elecciones presidenciales tenidas en el mes de julio para plantear una respuesta al nuevo gobierno. Saltando una serie de reuniones intermedias, la 'troika' europea (Alemania, Francia e Inglaterra) presenta a Irán una propuesta para que su Gobierno renuncie al proceso de enriquecimiento de uranio. Se trata de un documento de 34 páginas, que pueda servir de base para próximas discusiones. Irán podrá tener acceso a tecnología nuclear "dentro del marco de las ofertas internacionales". Se le garantiza un "aprovisionamiento permanente" de combustible nuclear para sus centrales con fines civiles, de manera que Irán renuncie a otras ambiciones militares. Europa dice estar disponible a ofrecerle ayuda en el ámbito de la seguridad. La 'troika' europea promete toda ayuda para que Irán pueda integrarse en la Organización Mundial del Comercio (OMC). Irán exporta el $80 \%$ de su petróleo a Europa y puede ser considerado como "una fuente de aprovisionamiento energético de largo plazo". Todas estas propuestas, a primera vista, pueden tomarse como un catálogo difuso de 'buenas intenciones' para abrir un nuevo capítulo de conversaciones. "“Última oferta europea a Irán antes de la ruptura”. Le Figaro, 6 de agosto de 2005) 
Si Teherán persiste en querer reabrir su central de conversión de uranio de Ispahán - primera fase en el enriquecimiento de uranio y, en última etapa, la fabricación de la bomba- el régimen iraní puede ser abocado ante el Consejo de Seguridad de Naciones Unidas. Tomando en cuenta que, desde el mes de febrero, Bush y Rice repiten sus amenazas a Irán, este país insiste en reiterar que no renunciará a la conversión y enriquecimiento de uranio. Para los europeos, estas actividades son injustificadas, porque desde hace tiempo los iraníes reciben combustible nuclear de parte de Rusia y también está garantizada la oferta europea para disponer de la energía nuclear para uso exclusivo civil. La propuesta europea busca ayudar a completar el proceso nuclear sin que Irán disponga del doble uso, civil y militar. Hay un cierto avance en la propuesta europea, por cuanto se reconoce el derecho de Irán a "desarrollar la investigación, la producción y la utilización de la energía nuclear, de conformidad con las obligaciones dictadas por el Tratado de No Proliferación Nuclear" (TNP, del cual Irán es país signatario). Se trata de energía nuclear civil. Esto supone una cierta evolución - dicen los europeos- con respecto al pasado reciente, cuando este derecho le fue negado a la República Islámica, juzgada como "poco confiable" por muchos gobiernos que, además piensan que Irán no necesita desarrollar la energía nuclear dada su riqueza petrolera. Como veremos enseguida a los dirigentes iraníes y al nuevo presidente no les agrada esta política del "palo y de la zanahoria" por ser considerado un país poco confiable. ("Irán califica como inaceptable' la propuesta europea para resolver la crisis nuclear”. Le Monde, 7 de agosto de 2005)

Un día más tarde, Irán reacciona: "Las propuestas europeas son inaceptables y no responden en lo más mínimo a nuestras esperanzas". El nuevo presidente iraní - sin referirse directamente al tema nucleardijo que su país "no se sometería al extranjero, ni sacrificaría su dignidad". Como estaba pactado, la deliberación pasa a consideración de los 35 gobernadores de la AIEA. (Le Monde, 7 de agosto de 2005) Con fecha 8 de agosto Irán reemprendió sus actividades en la fábrica de Ispahán. "La decisión es irreversible, incluso si el Consejo de gobernadores (AIEA) decide mañana enviar el informe iraní ante el Consejo de Seguridad, porque esto (la suspensión de actividades) no tiene un fundamento legal y es contrario al tratado de no proliferación", dijo el vicepresidente de la organización iraní de la energía atómica. "Irán ha reanudado la conversión de uranio bajo el control de la AIEA". "Yo estoy orgulloso, pero también temeroso, dijo uno de los jóvenes ingenieros de Ispahán; no pensaba que íbamos a reanudar el trabajo algún día". La central, considerada como un 
eslabón clave del programa nuclear, está protegida con decenas de baterías antiaéreas. En razón de las sospechas de una parte de la comunidad internacional y de negociaciones llevadas con los europeos sus actividades fueron detenidas en noviembre 2004. ("Irán reanuda sus actividades nucleares ultrasensibles, pese al riesgo de una crisis". Le Monde, 9 de agosto de 2005)

"La Organización Internacional de la Energía Atómica exige a Irán el cese de su actividad nuclear". Se trata de un voto por consenso, una resolución que insta a Irán a que paralice todas las actividades relacionadas con su programa de enriquecimiento de uranio, en referencia a la reapertura de la central nuclear de Ispahán, precintada desde noviembre de 2004 y que ayer entró de nuevo en funcionamiento. "La falta de consenso había impedido hasta hoy a la AIEA emitir una resolución sobre la crisis nuclear". En la línea de Bush y Rice, el representante de Estados Unidos "ha acusado al régimen de los ayatolas de abusar del derecho a acceder a la tecnología nuclear para fines pacíficos, así como por usar su programa atómico civil para enmascarar sus verdaderas intenciones militares”. Este es el cinismo de la Administración Bush, que atropellan todo derecho en la guerra de Irak y su Pentágono sigue fabricando y utilizando armas atómicas de bolsillo convencionales. Aunque esos temores fueran ciertos, no son los Estados Unidos el mejor juez que opina y condena.

La resolución expresa "una seria preocupación" por la reactivación de la planta, donde fueron retirados ayer los precintos de la OIEA que sellaban esa instalación, y piden a Mahomed el Baradei elaborar un informe antes del 3 de septiembre. Este informe técnico debe reflejar si Irán cumple todas las exigencias del Acuerdo de Salvaguardas del Tratado de No Proliferación. La resolución "urge" a Irán a "restablecer la plena suspensión voluntaria de todas las actividades relacionadas con el enriquecimiento", incluyendo la producción del gas que se introduce en centrifugadoras para enriquecer uranio. Además, insta a Teherán a que permita a la OIEA colocar nuevamente los precintos que fueron retirados de Ispahán. "En esta central no se enriquece uranio, pero sí el triturado y purificado de este mineral, un paso previo al enriquecimiento. Mediante este segundo proceso se fabrica combustible para alimentar a los reactores nucleares, pero también se puede emplear para fabricar bombas atómicas".

"Irán reitera que está en su derecho". "Irán, país del bloque de los no alineados que pertenece a la OIEA, pero no integra la Junta de Gobernadores, ha subrayado tras conocer el texto de la resolución que 
"no cederá" a las presiones para suspender sus actividades atómicas y "se convertirá en un productor de combustible (nuclear) en una década", en palabras del jefe de la delegación iraní ante la OIEA, Sirus Naseri. En declaraciones a la prensa tras concluir la reunión urgente de Viena, Naseri ha acusado a los países industrializados de negar el acceso a la producción de combustible nuclear mediante el enriquecimiento. Dicha negación "se limita ahora a Irán, pero será aplicada a todos los países en desarrollo si Irán cede", advierte el diplomático. Poniendo la guinda en el pastel, George W. Bush se felicita por esta determinación de la OIEA, agregando que "el mundo está de acuerdo en que Irán no debería tener los medios para desarrollar armamento nuclear". ("El Organismo Internacional de la Energía Atómica exige a Irán el cese de su actividad nuclear”. El País, 11 de agosto de 2005)

Cada día se agrega una nueva protesta desde el campo iraní, dando a entender la subida de tensión. El ex presidente iraní Hashemi Rafsanyani advirtió a Occidente que la decisión iraní en materia nuclear es irreversible: "No traten a Irán como tratan a Irak o Libia". La respuesta del público multitudinario ha sido: "Muerte a EE.UU", "Muerte a Israel" y "Dios es grande". "La decisión de Irán es irreversible". Irán alega que el enriquecimiento de uranio con fines civiles no contradice el Tratado de No Proliferación, del que es signatario, y reclama que es un derecho legítimo de cualquier Estado. El portavoz del ministerio de Asuntos Exteriores iraní, Hamid Reza Asefi, insiste en que Irán no cederá a las presiones internacionales y "no renunciará a sus legítimos derechos de desarrollar energía nuclear para fines pacíficos". Asefi recordó que estas actividades "no se han desviado de sus propósitos pacíficos y están bajo la supervisión de la OIEA". En cuanto a la resolución presentada ayer la calificó de "inaceptable" ya que "carece de principios jurídicos y lógicos" y se basa en una decisión "política, aprobada bajo la presión de EE.UU y sus aliados". Con esto se agudiza una tensión que nos recuerda los meses de enero-febrero 2003. " "Irán rechaza la resolución de la OIEA y considera la reactivación nuclear irreversible". El País, 12 de agosto de 2005).

Quienes conocen bien a George W. Bush dicen que él tiene dos características: que no aprende nada y no olvida nada, cualidades que no son las mejores para conducir al imperio más poderoso. Bush no ha aprendido que su presión sobre Afganistán, Irak, Irán, Corea del Norte es una de las razones principales por las que Irán y Corea del Norte quieran desarrollar energía nuclear; en el caso de Irán con fines civiles 
primordialmente, pero estarían dispuestos a ir hasta la fase final atómica, si esa es la única forma de no ser invadidos por Estados Unidos. Irak no hubiera sido atacado si sus científicos, en vez de invadir Kuwait, hubieran desarrollado la bomba atómica.

Un nuevo hecho confirma que Bush no aprende nada. En una entrevista de la televisión pública israelí, el mandatario estadounidense ha dicho que no se excluye el recurso a la fuerza contra Irán: "Todas las opciones están sobre la mesa. El recurso a la fuerza es la última opción para un presidente. Ustedes saben que hemos hecho uso de la fuerza recientemente para proteger la seguridad de nuestro país". Bush dijo que "él no quería recurrir a la fuerza sino en última instancia para dar seguridad al país y ofrecer a las personas la oportunidad de vivir en una sociedad libre". ("El presidente Bush no excluye el recurso a la fuerza contra Irán”. Le Monde, 12 de agosto de 2005)

$\mathrm{Al}$ escuchar estas palabras nos vienen a la mente algunas afirmaciones del discurso de G. W. Bush al inicio de su segundo mandato. "La supervivencia de la libertad en Estados Unidos depende del éxito de la libertad en el mundo entero. La mayor esperanza de paz en nuestra nación es el desarrollo de la libertad en el mundo entero. La política de Estados Unidos es apoyar y sostener los movimientos y las instituciones democráticas en todos los países y en todas las sociedades para poner fin a la tiranía en el mundo. Esto no se logra propiamente con las armas, pero nos defenderemos a nosotros y a nuestros amigos con la fuerza de las armas, si es necesario. Aquellos que viven en la tiranía y en la desesperanza deben saber que Estados Unidos no ignora su opresión, ni protege a sus opresores. Cuando defiendan su libertad estaremos con ellos. Mi principal deber es proteger a esta nación y a su pueblo contra nuevos ataques y posibles amenazas. Algunos, poco prudentes, han escogido poner a prueba nuestra determinación y han visto que era muy firme. El poder de Norteamérica no es ilimitado, pero, para dicha de los oprimidos, es considerable y lo utilizaremos con confianza para defender la libertad. No hay justicia sin libertad; no hay derechos humanos sin libertad". ("Bush: la supervivencia de la libertad en EE.UU. depende del éxito de la libertad en otros países”. El País, 20 de enero de 2005)

Extractamos algunos comentarios. El antiguo consejero del ex presidente estadounidense Jimmy Carter, Zbigniew Brzezinski, adoptó una posición crítica: "Si hubiera que tomar el discurso al pie de la letra, significaría una cruzada norteamericana a través del mundo entero". Otros 
muchos ven este discurso en forma muy seria: "El presidente ha dicho que la libertad de Norteamérica no está segura mientras no lo esté en el resto del mundo. Esta es una afirmación demasiado audaz. Sus implicaciones son considerables". Algunos republicanos tradicionales se sitúan entre los más críticos: "Bush ha afirmado el derecho a intervenir en los asuntos internos de cualquier país. Esto es la consigna para una guerra sin fin y la guerra es la muerte de las repúblicas", dijo Pat Buchanan, antiguo consejero de Reagan". (ECA, 2005; pp. 228-230)

Es triste llegar a esta conclusión, porque Bush ni aprende nada ni olvida nada. Siendo el presidente más votado en toda la historia de Estados Unidos, esta reelección consolida su fundamentalismo. Por añadidura, los ataques terroristas del 7 de julio en Londres y poco después en el balneario de Egipto han podido influir en la radicalidad de la sentencia de la OIEA, siempre por el temor de que una filial de Al Qaeda pueda apoderarse del arma atómica. La amenaza es cierta, pero cquién dio el banderillazo de salida en esta carrera del terrorismo?

Los diplomáticos europeos y de Estados Unidos dicen que si Irán mantiene su programa de conversión de uranio hasta el 3 de septiembre, cuando Mahomed el Baradei presente su informe, el contencioso nuclear será sometido al Consejo de Seguridad de la ONU. También en este punto hay una fuerte dosis de cinismo. Para juzgar y evitar esta clase de delitos de guerra, de lesa humanidad y genocidios, el Secretario General de Naciones Unidas pidió a los países que ratificaran los estatutos de la Corte Penal Internacional (CPI) y que acataran el juicio moral del Tribunal Internacional de Justicia. El poder de estas dos instituciones es el juicio moral de la comunidad internacional. El Consejo de Seguridad es muy poco representativo de dicha comunidad y menos lo son los cinco miembros permanentes con "poder de veto". El próximo mes de septiembre se reúne la Asamblea General de Naciones Unidas y tendrá que enfrentar serias reformas. Si el Consejo de Seguridad no es representativo ni fehaciente y si algunas de las grandes potencias no ratifican los estatutos de CPI, el derecho de la fuerza se impondrá siempre sobre la fuerza del derecho y el resultado será más terrorismo. Esperamos que en el próximo mes de septiembre la Asamblea General de Naciones Unidas evalúe objetivamente el informe sobre Irán que debe presentar Mahomed el Baradei, porque el "enigma nuclear" no se resuelve. 